\title{
A pesca artesanal e a sucessão geracional no município de Maracanã, estado do Pará, Brasil
}

\author{
Artisanal fishery and generational succession in Maracanã City, Pará State, Brazil
}

\author{
Laíse Carla Almeida da Conceição ${ }^{1}$ \\ Cyntia Meireles Martins ${ }^{2}$ \\ Marcos Antônio Souza dos Santos ${ }^{3}$ \\ Janayna Galvão de Araújo ${ }^{4}$ \\ Elideth Pacheco Monteiro ${ }^{5}$
}

\begin{abstract}
Resumo
A pesca artesanal é uma atividade tradicional de relevância socioeconômica e cultural no estado do Pará, envolvendo um grande número de pescadores que tem na atividade a base de sua economia familiar. Contudo, diversos fatores concorrem para que a pesca não tenha as condições de sucessão familiar adequadas à sua reprodução geracional, mantendo as gerações mais novas na atividade. Nesses termos, o estudo analisou a sucessão geracional entre jovens pescadores artesanais no município de Maracanã, na região do Salgado, nordeste do Pará. Os dados foram levantados em 2017 por meio de entrevistas em profundidade com as instituições de apoio à atividade, e no ano de 2018 com aplicação de questionários aos pescadores que realizavam a atividade em conjunto com seus pais. Os resultados apontam que a idade média desses pescadores é 31,5 anos, sendo que $26,67 \%$ deles possui apenas o ensino fundamental incompleto. O longo tempo de jornada de trabalho foi o principal fator de abandono da escola. Apesar da satisfação relatada por $36 \%$ dos pescadores entrevistados, eles não desejam que seus filhos sigam na profissão. Os problemas relatados foram a falta de documentação que comprove o exercício da atividade, falta de apoio institucional, aumento dos riscos e a pesca industrial exacerbada, que interfere no maior esforço da pesca artesanal. Aponta-se a necessidade de maior integração para o trabalho cooperativo, apoio institucional a fim de facilitar os meios de financiamentos bancários, de orientação técnica ao profissional da pesca e maior fiscalização da pesca industrial.
\end{abstract}

Palavras-chave: Pesca artesanal. Sucessão familiar. Nordeste paraense.

\begin{abstract}
Artisanal fishery in Pará is a traditional activity of socioeconomic and cultural relevance in the state, involving a vast number of workers whose job is the basis of their housekeeping. However, several factors contribute to the fact that fishing does not have the conditions of family succession appropriate to its generational reproduction, keeping younger generations in the activity. Thus, the study analyzed the generational succession among young artisanal fishers in the municipality of

\footnotetext{
${ }^{1}$ Engenheira Agrônoma. Universidade Federal Rural da Amazônia (UFRA). E-mail: laise.agronomia@gmail.com.

${ }^{2}$ Engenheira Agrônoma. Doutora em Ciências Agrárias. Professora da Universidade Federal Rural da Amazônia (UFRA). E-mail: cyntiamei@hotmail.com.

${ }^{3}$ Engenheiro Agrônomo. Doutor em Ciência Animal. Professor do Programa de Pós-Graduação em Agronomia da Universidade Federal Rural da Amazônia (UFRA). E-mail: marcos.santos@ufra.edu.br.

${ }^{4}$ Engenheira de Pesca. Doutoranda em Ecologia Aquática e Pesca pela Universidade Federal do Pará (UFPA). E-mail: janaynagalvao@yahoo.com.br.

${ }^{5}$ Engenheira de Pesca. Doutoranda em Agronomia pela Universidade Federal Rural da Amazônia (UFRA). E-mail: elidethpacheco@hotmail.com.
} 
Maracanã, in the Salgado region, northeast of the State of Pará. The data was collected in 2017, by questionnaires applied to fishers who performed the activity in conjunction with their parents. The results indicate that the average age of these fishers is 31.5 years, and $26.67 \%$ of them did not finish elementary school. Many working hours was the main factor in school dropout. Despite the satisfaction reported by $36 \%$ of fishers interviewed, they do not want their children to follow the profession. The problems reported were lack of documents corroborating the work performance, lack of institutional support, increased risks, and exacerbated industrial fishing, which interferes with the efforts of the artisanal fishery. There is a need for greater integration into cooperative work, institutional support to facilitate bank financing and technical guidance for the fishing professional and greater oversight of industrial fishery.

Keywords: Artisanal fishery. Family succession. Northeastern Pará.

\section{Introdução}

A pesca artesanal é uma atividade extrativista praticada na Amazônia, tradicionalmente, desde antes da colonização portuguesa (ISAAC et al., 2006). Essa atividade assume grande importância na região, proporcionando alimento, ocupação de mão de obra e renda para um grande contingente populacional, especialmente para as comunidades ribeirinhas (SANTOS, 2005).

O Pará é o segundo maior produtor nacional de pescado (RAINHA, 2014). As estatísticas referentes ao ano de 2010 indicam que o estado foi responsável por 47,02\% da produção da Região Norte e 10,32\% da produção nacional (MPA, 2012), sendo a atividade derivada de três segmentos: a pesca artesanal, a pesca industrial e a aquicultura, sendo a pesca artesanal realizada em praticamente todos os municípios do estado do Pará e correspondendo a 84,23\% da produção.

Na região do estudo compreendida no Salgado Paraense, a proximidade com o Oceano Atlântico evidencia outras características nas atividades envolvidas na pesca, com as embarcações motorizadas de pequeno e médio porte, petrechos de pesca e insumos rústicos, adquiridos localmente ou confeccionados pelo próprio pescador, como redes de arrasto, espinhéis e currais (SANTOS, 2005; NOGUEIRA; SOUZA; SANTA BRÍGIDA, 2017).

Nessa região o tempo para a execução da atividade pesqueira costuma ser mais longo, com a realização de viagens aos chamados "ranchos" (casebres construídos em locais estratégicos para a pesca, geralmente, longe das residências dos pescadores) que podem durar mais de uma semana (NOGUEIRA; SOUZA; SANTA BRÍGIDA, 2017).

As famílias de pescadores artesanais são grupos que possuem uma cultura específica. Em geral, essas populações possuem conhecimentos sobre a natureza e seus dinamismos que atravessam várias gerações (PAIOLA; TOMANIK, 2002). As práticas artesanais são aprendidas no 
convívio familiar e no contato direto com a natureza, bem como são utilizadas por pescadores e seus familiares visando à sua reprodução socioeconômica.

A sucessão geracional, dentro de unidades familiares tradicionais, é um processo importante para a reprodução social das famílias, semelhante ao trabalho que ocorre na agricultura familiar, sendo repassado como herança aos familiares. Dessa forma, a pesca artesanal também se trata de uma ocupação profissional aprendida pelos filhos com seus pais. Os pescadores possuem em seu trabalho a principal fonte de renda familiar e os pais, costumeiramente, repassam seus conhecimentos aos filhos. Ressalte-se que são poucas as publicações concernentes à sucessão geracional dentro do contexto do ofício de pescador artesanal, mas ambas as atividades (agricultura e pesca) possuem, geralmente, mão de obra familiar, bem como a reprodução geracional semelhante.

Este trabalho visa analisar como a atividade da pesca se mantém diante das condições de sucessão, uma vez que os processos migratórios de jovens tornam o meio rural mais idoso e masculinizado, e quais os atores que irão dar continuidade ao atual quadro da atividade pesqueira no município de Maracanã.

\section{A sucessão geracional e a pesca}

Entende-se por sucessão geracional a criação de uma nova geração de indivíduos que permanecem na atividade de produção de alimentos e que assumem o comando da atividade econômica praticada pela família. Os filhos são os possíveis sucessores e a permanência ou não deles na atividade dependerá de condições objetivas internas e externas ao contexto em que vivem. No Brasil, em geral, a sucessão geracional é endógena, ou seja, são os próprios familiares que geram seus sucessores (BRUMER, 2007; STROPASOLAS, 2011).

A sucessão não é meramente um evento de transferência da atividade entre membros da família, mas um processo do controle do empreendimento, da transferência de conhecimento técnico adquirido ao longo dos anos e que ocupa um extenso período de tempo. Essa transferência, modo geral, ocorre do pai para o filho, o qual assume a gestão da atividade quando o pai já não possui mais condições de realizá-la. Esse processo ocorre de forma gradual, sendo os ensinamentos repassados de forma planejada para o sucessor (MIRALHA; HESPANHOL, 2003).

Conforme Stropasolas (2011, p. 1), a sucessão geracional ocorre "com a transferência de poder e do patrimônio entre gerações no âmbito da produção agrícola familiar”, isto é, com “a 
retirada paulatina das gerações mais idosas da gestão do estabelecimento e a formação profissional de um novo agricultor”. Costa (2010, p. 159) acrescenta a discussão que o processo sucessório ocasiona uma nova formatação de pessoas que tomam como base três pilares: transferência patrimonial; continuação da atividade profissional paterna; e a retirada das gerações mais velhas da gestão do patrimônio.

Abramovay (1992, p. 191) corrobora com a discussão ao destacar que a sucessão geracional "não pode ser confundida com herança ou divisão patrimonial" e que envolve uma preparação. Portanto, deve ser entendida como um "processo, e não apenas como a troca de um gestor por outro" (KIYOTA; PERONDI, 2014).

Quanto ao trabalhador da pesca, este, apesar de desenvolver uma das profissões mais antigas do mundo, encontra uma série de constrangimentos econômicos que refletem na sua geração de renda e qualidade de vida, especialmente no estado do Pará (SANTOS, 2005; BORCEM et al., 2011; AGUIAR; SANTOS, 2012; SANTANA et al., 2014).

As opções de trabalho remunerado constituem os principais atrativos da não continuidade dos filhos na atividade da pesca, além das dificuldades da vida e trabalho (BRUMER, 2014). Para Silveira, Serafin e Siqueira (2012, p. 05), embora ainda na atualidade o saber seja transmitido de pai para filho, os pescadores não mais incentivam seus filhos a seguirem essa profissão, levantando o questionamento de como será o estado da pesca artesanal nos próximos anos.

\section{Metodologia}

A pesquisa de campo foi desenvolvida no município de Maracanã, no nordeste paraense, microrregião do Salgado. A pesca artesanal, ao lado da agricultura de base familiar, constitui-se na atividade de maior importância econômica no município (AGUIAR; SANTOS; ALMEIDA, 2010). Atualmente, Maracanã possui uma população aproximada de 28 mil habitantes, distribuída em uma superfície de 855 km² (IBGE, 2019).

Os dados deste trabalho foram obtidos em duas etapas. Inicialmente, em julho de 2017, foram realizadas entrevistas em profundidade com as instituições envolvidas na atividade de pesca, a fim de realizar um panorama geral da pesca em Maracanã, bem como identificar os problemas inerentes à atividade que contribuem para desmotivar a sucessão pesqueira. As entrevistas foram realizadas com a presidente da Associação da Reserva Extrativista (Resex) Marinha de Desenvolvimento Sustentável de Maracanã; presidente do Sindicato dos Pescadores e Aquicultores 
Artesanais de Maracanã (Sipaam); Técnico da Empresa de Assistência Técnica e Extensão Rural do Pará (Emater) e Técnico da Secretaria Municipal de Agricultura de Maracanã.

Ressalta-se que não foi entrevistado nenhum representante da Colônia de Pescadores Artesanais do município (Z-07), pois no momento da visita à instituição o prédio estava em reforma e sem organização de seus arquivos.

Após as entrevistas, no mês de novembro de 2018, aplicou-se 30 questionários aos homens que desenvolvem a atividade pesqueira, preferencialmente, jovens ou aqueles que ainda a desenvolviam juntamente com seus pais. Os questionários englobaram aspectos socioeconômicos (idade, escolaridade, local de origem, pessoas que vivem no domicílio), sobre os irmãos e permanência na pesca (sexo, idade, trabalho, escolaridade, o que motivou os irmãos a trabalharem fora da atividade pesqueira, a probabilidade de assumir a atividade da pesca, o nível de satisfação quanto à atividade pesqueira e as suas vantagens), a percepção da comunidade para cada entrevistado (organizações sociais existentes na comunidade, a frequência de visitação, a condição de vida nos últimos 12 meses, eficiência na produção de alimentos por comparação da situação atual em relação aos 5 anos anteriores), e sobre a atividade da pesca artesanal (auxílio à assistência técnica, financiamentos bancários e a situação diante dos bancos).

A aplicação usou o método snowball sampling, em que um respondente indica o outro. Ressalta-se que a técnica proporcionou evidenciar os pescadores de maior reconhecimento em Maracanã, tradição na família, conhecimento empírico e prática no manejo de recursos naturais.

As respostas quantitativas, a partir dos dados coletados, foram organizadas em um banco de dados e submetidas à análise estatística em planilha eletrônica do LibreOffice versão 6.3 .5 para elaboração de tabelas. As demais informações foram analisadas qualitativamente, sendo discutidas de forma textual, além de observação in loco.

\section{Resultados e discussão}

\section{$O$ contexto da atividade da pesca em Maracanã}

O município de Maracanã é extenso, são 105 vilas e cerca de 90\% pertence à Área de Proteção Ambiental (APA) e Reserva de Desenvolvimento Sustentável. No tocante à ação institucional, a responsabilidade da atividade pesqueira é da Secretaria de Agricultura, que atua principalmente no apoio à produção de açaí e hortaliças, os quais possuem maior representatividade produtiva no município. A prefeitura distribui a produção agrícola com o apoio da Secretaria na 
Ceasa de Belém e em feiras de outros municípios. A pesca continua sendo uma das principais atividades desenvolvidas no município, contudo o fomento institucional não ocorre pari passu à sua relevância.

Conforme os entrevistados, os pescadores se ressentem de assessoria técnica, ou seja, o acesso ao conhecimento e à informação é deficiente. Ademais, existe pouca articulação das instituições envolvidas para o trabalho cooperativo, quer seja por conflitos internos, especialmente entre as organizações sociais, quer seja pela falta de confiança entre os pescadores, além da falta de cultura organizativa.

No que tange às representações sociais, em Maracanã existe a Colônia de Pescadores Z-07, sendo uma das mais antigas do estado do Pará, fundada em 29 de junho de 1916 e, atualmente, conta com cinco capatazias, envolvendo aproximadamente 2.000 filiados. No município também tem o Sindicato dos Pescadores e Aquicultores Artesanais de Maracanã (Sipaam), fundado em 05 de março de 2006, sendo o primeiro sindicato dos pescadores artesanais do Brasil. O Sipaam possui 400 aposentados, 2.362 ativos sindicalizados e 56 pescadores inativos. A grande maioria procura o sindicato quando está próximo do período de aposentadoria e o sindicato age com apoio da prefeitura apenas para expedição de documentos. Conforme relatado em entrevista, o Sipaam não possui vínculo direto com a Colônia Z-07, pois surgiu como forma de rompimento de relação por ela não dispor de credibilidade perante a categoria.

Quanto à atividade pesqueira, observou-se que a safra ocorre entre os meses de maio a julho. Nesse período, Maracanã também recebe pescadores de outros municípios, como Bragança, São Caetano de Odivelas e Vigia, que se deslocam para exercer a atividade. Em Maracanã, as comunidades mais representativas na pesca são Mocooca (que realiza a pesca em rede de estacada), 40 do Mocooca, Nazaré do Seco, Vila do Penha (com tradição na pesca de espinhel), Curuçazinho e Mota (que realiza mais fortemente a pesca de curral).

A localidade com maior quantitativo de pescadores é a Vila do Penha, por sua proximidade com o oceano. Nessa localidade, a produção apresenta pouca oscilação ao longo do ano. São comuns atravessadores no local, que possuem baús com freezer e transacionam o peixe em Salinas, São João de Pirabas e Capanema. O mercado local também é aquecido em virtude do grande consumo interno.

Não existe por parte do poder público municipal um controle de produção e comercialização, em virtude do fácil acesso a outras localidades, o que dificulta os registros do 
quantitativo de pescado e de valores comercializados. Contudo, sabe-se que a pressão do mercado tem tornado o esforço de pesca maior e diminuído a oferta de algumas espécies nos últimos anos.

Foi citado, por exemplo, que alguns barcos ficam 10 dias no mar; nesse período, a alimentação termina ou se torna escassa e a tripulação não consegue capturar uma quantidade que cubra os custos do esforço de pesca, havendo em muitos casos prejuízos financeiros. Outras dificuldades mencionadas pelos pescadores foram a subnutrição e anemia em alto-mar (alimentação somente à base de peixe, farinha e enlatados); o alto índice de consumo de álcool e drogas; e mortes por afogamento.

O pescador artesanal do município não é comtemplado com o seguro defeso, pois se justifica que a pesca na região é realizada em mar aberto. Esse é um fato preocupante, pois o município é tradicional na atividade pesqueira, mas não conta com a política implementada de forma a beneficiar os pescadores e proteger os estoques por meio da proibição da pesca no período de defeso. Verifica-se, assim, que a política do defeso ainda precisa adotar melhores critérios e fiscalização dos beneficiários, visto que é recorrente situações de fraudes que dificultam o acesso de quem realmente precisa (MARINHO, 2009).

Entre agosto e setembro vários barcos capturam camarão, mas também arrastam os peixes, mesmo aqueles com baixo valor comercial. Segundo o presidente do sindicato, a falta de controle no uso do recurso natural evidencia a posição desigual na qual se encontra o pescador artesanal face à "concorrência" com grandes empresas pesqueiras. Nesses termos, a atuação da pesca industrial em Maracanã coexiste com os pescadores artesanais de maneira desigual, devido ao arrasto de peixes, independente de tamanho ou espécie. Conforme relatado também pela presidente da associação da Resex de Maracanã, a despeito do prejuízo ao pescador artesanal, a pesca de arrasto industrial não é proibida na região, acarretando a curto prazo em redução de espécies capturadas.

Fora a problemática da pesca industrial, outro fator que diminui a possibilidade do pescador de auferir maiores retornos econômicos é que o município não processa seu pescado, apesar da tradição pesqueira do local, sendo ele transacionado $100 \%$ in natura para outras regiões. Assim, o não processamento visando agregar valor e os menores preços pagos pelo produto constitui um ponto de estrangulamento da atividade.

No que tange ao acesso ao crédito, evidenciou-se no município altos índices de inadimplência dos projetos desde a década de 1990, com financiamentos para barcos e petrechos de pesca. Quanto ao custeio da atividade, grande parte dos pescadores realiza o esforço de pesca através do aviamento feito pelo chamado "patrão de pesca", que entrega ao pescador combustível 
para o barco, alimentação, dentre outras necessidades primárias e, posteriormente, fica com parte do pescado após a chegada do pescador. Essa forma de custeio por aviamento, certamente, apropria-se de grande parcela da renda dos pescadores, causando um ciclo vicioso de empobrecimento do pescador artesanal.

Sobre a sucessão geracional na pesca, foi citado que o desestímulo do jovem ocorre por ele acompanhar as dificuldades encontradas pelo pai, o que desestimula sua permanência na atividade. Devido à exaustão do recurso pesqueiro, o esforço de pesca é ampliado, acarretando maiores problemas de saúde (problemas de coluna e de pele devido a maior exposição ao sol) e maiores riscos à atividade como roubo e afogamento. Ademais, há uma vulnerabilidade ao uso de drogas e prostituição, tornando o pescador pouco resiliente na atividade.

Conforme o Pescador 1, "antes tinha gente que educava sua família apenas com a produção do curral; hoje você não vê mais isso. O próprio pai incentiva outra atividade". Como decorrência do problema da sucessão e do envelhecimento do profissional da pesca, argumentou que "o dono da embarcação tem problema até para arrumar gente para pescar".

Mendonça et al. (2017, p. 146), estudando a evolução da pesca no litoral paranaense em série temporal de 2005 a 2015, mostraram o setor em declínio quanto à entrada de novos pescadores, aumento da idade média dos pescadores e problemas de sucessão familiar, comprometendo a perda de memória social e identidade por meio da transmissão entre gerações de conhecimentos e práticas da pesca.

\section{Aspectos socioeconômicos}

Nesse contexto, buscou-se avaliar os jovens ou aqueles que ainda desenvolviam, juntamente com seus pais, a atividade da pesca. Todos os entrevistados foram do sexo masculino. A idade média dos entrevistados no município de Maracanã foi de 31,5 anos, ocorrendo 50\% com idade abaixo de 29 anos, 30\% de 30 a 39 anos e 20\% com idade acima de 40 anos. Quanto à escolaridade, 26,67\% concluíram o Ensino Fundamental e apenas um pescador terminou o Ensino Médio, conforme a Tabela 1. Dentre os entrevistados, $60 \%$ não concluíram o Ensino Fundamental, sendo todos com idade superior a 20 anos. Tal situação foi justificada pela falta de tempo, pois muitas vezes as pescarias levam semanas, impedindo que os jovens pescadores frequentem regularmente a escola.

Mendonça et al. (2017, p. 146), ao estudarem a socioeconomia da pesca no Paraná, identificaram que ainda que a idade média do pescador tenha aumentado de 2005 a 2015, passando 
de 44 para 44,8 anos, durante o período analisado esse trabalhador se manteve com o perfil de apenas ensino fundamental incompleto. Cabe ressaltar que os filhos dos pescadores não têm seguido a atividade dos pais quando buscam maior nível de instrução. Assim, tem-se uma relação inversamente proporcional, considerando que quanto maior o nível de instrução, maior a probabilidade de o filho desse pescador evadir da atividade pesqueira.

TABELA 1 - RELAÇÃO DA ESCOLARIDADE COM FAIXAS ETÁRIAS DE JOVENS PESCADORES DE MARACANÃ

\begin{tabular}{|c|c|c|c|c|c|}
\hline & \multicolumn{5}{|c|}{ Escolaridade } \\
\hline & $\begin{array}{l}\text { Fundamental } \\
\text { incompleto }\end{array}$ & $\begin{array}{l}\text { Fundamental } \\
\text { completo }\end{array}$ & $\begin{array}{l}\text { Ensino Médio } \\
\text { incompleto }\end{array}$ & $\begin{array}{l}\text { Ensino Médio } \\
\text { completo }\end{array}$ & Total \\
\hline Faixa etária & $\%$ & $\%$ & $\%$ & $\%$ & $\%$ \\
\hline 16 a 19 anos & & 3,33 & & 3,33 & 6,70 \\
\hline 20 a 29 anos & 23,33 & 16,67 & & 3,33 & 43,30 \\
\hline 30 a 39 anos & 16,67 & 6,67 & 6,67 & & 30 \\
\hline $\begin{array}{c}\text { Acima de } 40 \\
\text { anos }\end{array}$ & 20 & & & & 20 \\
\hline Total & 60 & 26,67 & 6,67 & 6,67 & 100 \\
\hline
\end{tabular}

FONTE: Os autores.

As atividades tradicionais da área rural se reduzem, muitas vezes, a única opção aos que não puderam estudar ou inserir-se em outros mercados de trabalho (CARNEIRO, 1998). Em outras palavras, há uma desvalorização da atividade cujo aprendizado se dá geralmente fora da escola, que é a forma consagrada de qualificação profissional, ao passo que, atualmente, vê-se o crescente aumento de escolarização dos jovens em relação às gerações anteriores, imprimindo nos jovens rurais uma visão negativa sobre as atividades agrícolas (CHAMPAGNE, 1986) e da pesca (MENDONÇA et al., 2017), ocasionando ruptura no processo da sucessão geracional.

A maioria dos jovens entrevistados (90\%) nasceu em comunidades pertencentes ao município de Maracanã, mostrando a baixa mobilidade no espaço. Encontra-se resultado semelhante no trabalho de Santos (2005, p. 69) na região do Salgado paraense. Segundo o autor, a pouca saída dos atores sociais pode ser atribuída às poucas oportunidades de trabalho na região que, geralmente, restringem-se à agricultura familiar e à própria pesca artesanal. 
Com relação ao número de pessoas na família, 70\% deles residem com 3 a 5 pessoas. No trabalho de Garcez e Botero (2005, p. 21), a média de pessoas morando no mesmo domicílio de pescadores é de 4 pessoas. Esses dados apontam para uma nova configuração familiar dentro de comunidades tradicionais, o que foi observado no trabalho de Rodrigues et al. (2017, p. 107), reflexo das novas dinâmicas sociais que reduzem o número de filhos por família, mesmo naquelas comunidades rurais que, anteriormente, valiam-se do aumento dos componentes da família como maior força de trabalho braçal, sendo esse fator determinante para garantir sua reprodução socioeconômica. Contudo, nota-se que o fenômeno da redução do número de componentes das famílias rurais é mais lento comparativamente ao observado no meio urbano (ALVES; MOTA, 2012), constituindo fator de diferenciação.

\section{Sobre os irmãos e a permanência na pesca}

A Tabela 2 refere-se ao número de irmãos dos entrevistados, compreendidos pelo sexo, faixa etária e escolaridade. Dentre os jovens pescadores entrevistados, $42 \%$ possuem irmãs e 58\% são pertencentes ao sexo masculino. Quando se observa o perfil educacional dos irmãos dos entrevistados, nota-se que essa população possui maior nível de instrução formal, conforme observado nos estudos de Costa et al. (2013, p. 80) e Figueiredo et al. (2014, p. 3230).

$\mathrm{Na}$ amostra estudada, acerca dos entrevistados que sabiam responder sobre a educação de seus irmãos, 30,8\% afirmam que suas irmãs não concluíram o ensino fundamental, ao passo que também 30,8\% conseguiram finalizar o ensino médio. Com relação aos irmãos, $25 \%$ possuem o ensino fundamental incompleto e apenas $2,8 \%$ dos seus irmãos possuem o ensino médio completo.

TABELA 2 - SEXO, FAIXA ETÁRIA E ESCOLARIDADE DOS IRMÃOS DOS JOVENS PESCADORES ENTREVISTADOS EM MARACANÃ

\begin{tabular}{|c|c|c|c|c|c|c|c|}
\hline \multirow[b]{2}{*}{ Sexo } & \multirow[b]{2}{*}{$\begin{array}{l}\text { Faixa } \\
\text { etária }\end{array}$} & \multicolumn{5}{|c|}{ Escolaridade } & \multirow[b]{2}{*}{$\begin{array}{c}\text { Total de } \\
\text { irmão }\end{array}$} \\
\hline & & $\begin{array}{l}\text { Fund. } \\
\text { Inc. }\end{array}$ & $\begin{array}{l}\text { Fund. } \\
\text { Compl. }\end{array}$ & $\begin{array}{l}\text { Ens. Méd. } \\
\text { Inc. }\end{array}$ & $\begin{array}{c}\text { Ens. Méd. } \\
\text { Compl. }\end{array}$ & $\begin{array}{c}\text { Não } \\
\text { souberam } \\
\text { responder }\end{array}$ & \\
\hline \multirow{5}{*}{ 挛 } & & $\%$ & $\%$ & $\%$ & $\%$ & $\%$ & $\%$ \\
\hline & Menor de 19 & & 3,8 & & 3,8 & & 3,2 \\
\hline & 20 a 29 & 11,5 & & & 7,7 & 7,7 & 13 \\
\hline & 30 a 39 & 7,7 & 3,8 & 7,7 & 11,5 & & 13 \\
\hline & Maior de 40 & 11,5 & 3,8 & 3,8 & 7,7 & 3,8 & 13 \\
\hline \multicolumn{2}{|c|}{ Total feminino } & 30,8 & 11,5 & 11,5 & 30,8 & 11,5 & 42 \\
\hline
\end{tabular}




\begin{tabular}{|c|c|c|c|c|c|c|c|}
\hline \multirow{4}{*}{ 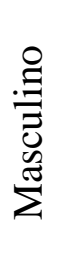 } & \multicolumn{2}{|l|}{ Menor de 19} & \multicolumn{3}{|l|}{2,8} & \multirow{2}{*}{$\begin{array}{l}13,9 \\
33,3\end{array}$} & \multirow{2}{*}{$\begin{array}{l}9,7 \\
27\end{array}$} \\
\hline & 20 a 29 & 5,6 & 2,8 & 5,6 & & & \\
\hline & 30 a 39 & 8,3 & & 2,8 & 2,8 & 5,6 & 11 \\
\hline & Maior de 40 & 11,1 & 5,6 & & & & 9,7 \\
\hline \multicolumn{2}{|c|}{ Total masculino } & 25,0 & 11,1 & 8,3 & 2,8 & 52,8 & 58 \\
\hline
\end{tabular}

FONTE: Os autores.

Nota-se que as irmãs dos pescadores apresentam maiores percentuais para níveis de estudo mais elevados (Tabela 2). Para Abramovay et al. (2001, p. 03), os rapazes apresentam menos chances ao acesso à educação, pois auxiliam na complementação da renda familiar. Essa divisão por sexo na atividade pesqueira entre os mais jovens é fator determinante quanto à perspectiva de futuro. Assim, os jovens do sexo masculino, tradicionalmente, abandonam os estudos mais cedo para ajudar seus pais na pesca, enquanto as mulheres trabalham nas tarefas domésticas, conseguindo administrar melhor tais atividades em combinação com os estudos.

Esse distanciamento da mulher nas atividades pesqueiras induz essas jovens mulheres a projetarem suas vidas fora da atividade da família (tecer redes, restaurar petrechos, catar mariscos, dentre outras). Assim, as jovens investem em estudos e buscam alternativas de inserção profissional no mercado de trabalho urbano. De toda forma, os pescadores têm incentivado os filhos a estudarem, orientando os jovens para outras perspectivas, o que os afasta do universo de trabalho da pesca (BORCEM et al., 2011). Nesta pesquisa, os entrevistados citam que os irmãos que não exercem a atividade têm trabalhado como pedreiro, camelô e motorista. Dentre as mulheres, irmãs dos pescadores entrevistados, a maior parte atua como donas de casa, babá, manicure e diarista.

Quando questionados sobre a probabilidade em assumir futuramente a atividade no lugar do pai, $76,6 \%$ responderam ser muito provável e, destes, $36,7 \%$ se sentem muito satisfeitos com a atividade pesqueira, e $10 \%$ se sentem insatisfeitos, o que pode ser entendido pela fala do Pescador 2: "tem muito barco industrial que tem diminuído a quantidade de peixes e o lucro, mas não o trabalho".

Dentre os $20 \%$ dos entrevistados que responderam ser pouco provável que assumam a sucessão da pesca, $13,4 \%$ se sentem relativamente insatisfeitos, também por perceberem a queda na quantidade de pescados devido ao aumento da pressão da pesca industrial sobre o recurso natural.

De acordo com os pescadores, a principal vantagem que encontram na atividade é o acesso ao lazer, respondido por $76,7 \%$ das pessoas. Os entrevistados comentam sobre o gosto pela 
profissão, a atração pelas águas e o prazer em ver suas embarcações cheias de pescado. Essas sensações positivas dão à atividade o sentido de lazer, o que pode ser percebido na afirmação do Pescador 3: "trabalho com muito esforço, mas é prazeroso, alegre. Fico mais animado ainda quando vejo os peixes".

Assim, é possível perceber prazer na atividade, fato afirmado por Brasil (2009, p. 128): “[...] na fala dos pescadores [há] o prazer na realização do ofício. Vínculos afetivos são construídos, gerando cooperação. Ressaltam que o trabalho em parceria demanda confiança, posto que até mesmo a vida do pescador depende da ajuda do parceiro de trabalho".

Outras vantagens respondidas por 30\% dos entrevistados são a de compra de bens materiais que a atividade proporciona, reconhecimento pela comunidade e a valorização profissional.

\section{Percepção dos pescadores sobre as organizações sociais, o apoio institucional e bem-estar}

A organização social é importante para a construção da percepção de bem-estar em que o indivíduo está inserido e, consequentemente, sua permanência na atividade. As relações sociais reforçam sentimentos de confiança, senso de pertencimento e bem-estar em jovens, tendo um papel tão importante quanto o aspecto econômico na opção dos jovens em permanecer ou não na atividade econômica da família (KISCHENER; KIYOTA; PERONDI, 2015).

A pesquisa realizada mostra que $96,7 \%$ das pessoas participam de algum tipo de organização (entre igrejas, associação, sindicato e clube de futebol). Porém, essa resposta não é satisfatória quando se analisa o vínculo à colônia e ao sindicato dos pescadores, que são de 36,7\% e $20 \%$, respectivamente, e apenas 6,7\% participam de ambos. Sousa et al. (2015, p. 93) e Mendonça et al. (2017, p. 150) afirmam que essas organizações, a despeito de objetivarem melhorias ao setor, possuem uma grande deficiência em relação a sua organização de forma a atender às demandas de seus associados.

Todos os pescadores entrevistados responderam não receber assistência técnica, mesmo com a presença da Emater no município. Nenhum deles possui carteira de identificação de pescador artesanal e não fizeram qualquer tipo de financiamento para a atividade no último ano, apesar de estarem adimplentes nos bancos. Alguns pescadores emitiram comentários sobre assistência técnica e financiamento. O Pescador 4 afirmou que "em outros municípios há assistência, mas aqui [município de Maracanã] é devagar" e o Pescador 5 disse que "há muito que melhorar para o pescador artesanal, tem muita falta de respeito por parte de pescadores industriais, falta apoio governamental para diminuir a burocracia para conseguir a carteira de pescador...”. 
A despeito das dificuldades de apoio institucional, comparando com os últimos cinco anos, $60 \%$ dos entrevistados responderam estar em melhor situação em relação ao bem-estar; mas 23,3\% e 16,7\% alegaram estar na mesma situação ou pior, respectivamente, uma vez que a pesca industrial tem avançado consideravelmente, dificultado a pesca artesanal e, consequentemente, afetado a renda desses trabalhadores, considerada fundamental na percepção dos trabalhadores para o bemestar. Destaca-se que metade dos entrevistados (50\%) respondeu que o ofício da pesca cobre apenas uma parcela das necessidades do lar. Conforme disse o Pescador 6: "a tendência é piorar; cada dia tem que buscar o peixe mais longe".

Eles ressaltaram ainda que, embora gostem da profissão e considerem a comunidade um bom lugar para viver, não desejam que seus filhos e netos continuem nela, fato destacado por todos os entrevistados. Contudo, mesmo com todas as dificuldades enfrentadas na pesca no município de Maracanã, "sempre haverá outros rapazes que continuarão a pescar, apaixonados pela maré", conforme o Pescador 7.

\section{Conclusão}

Os jovens pescadores do município de Maracanã herdaram seu conhecimento da atividade exercida pelos pais. Eles possuem, em sua maioria, o ensino fundamental incompleto, devido o extenso período de atividade laboral. A pesca industrial maciça tem diminuído a quantidade de peixes em locais mais próximos do município, obrigando os pescadores a migrarem para áreas cada vez mais distantes, dificultando o trabalho.

Ainda assim, eles acreditam que provavelmente substituam os pais na atividade, embora nem todos se sintam satisfeitos com a pesca e seu retorno financeiro, este, atrapalhando nas possíveis melhorias do domicílio e em cobrir as necessidades do lar.

O esforço ressaltado pelos entrevistados não diminui o amor pelo ofício, mas gera hesitação no que se refere ao desejo de ver seus filhos continuando na profissão de pescador artesanal. Pelos dados levantados e depoimentos dos pescadores, avulta-se a necessidade de maior integração para o trabalho cooperativo, apoio institucional a fim de facilitar os meios de financiamentos bancários e de orientação técnica, além de maior fiscalização da pesca industrial como forma de melhorar a gestão dos recursos pesqueiros.

\section{Agradecimentos}


Agradecemos o apoio do Conselho Nacional de Desenvolvimento Científico e Tecnológico, pelo financiamento do projeto "Governança e Cadeia Produtiva da Pesca: a socioeconomia e a relação entre os atores e as instituições nos municípios de Curuçá, Maracanã e Salinópolis - Pará” no âmbito do Edital Universal - MCTI/CNPq, n. 14/2013.

\section{Referências}

ABRAMOVAY, R. Paradigmas do capitalismo agrário em questão. Campinas: Unicamp, 1992.

ABRAMOVAY, R.; SILVESTRO, M. L.; MELlO, M. A.; DORIGON, C.; BALDISSERA, I. T. Agricultura familiar e sucessão profissional: novos desafios. In: Congresso Brasileiro de Economia e Sociologia Rural, 39, 2001, Brasília: Sober, p. 1-10.

AGUIAR, C. G. G.; SANTOS, M. A. S.; ALMEIDA, R. H. C. Estudo exploratório da cadeia produtiva da pesca artesanal no município de maracanã, estado do Pará. In: II Encontro da Sociedade Brasileira de Sociologia da Região Norte, 2010, Belém, 13 a 15 de setembro, p. 1-16.

AGUIAR, A. F. N; SANTOS, M. A. S. Percepções socioambientais de pescadores artesanais do distrito de São João do Abade, município de Curuçá, estado do Pará. Amazônia: Ciência \& Desenvolvimento, Belém, v. 8, n. 15, p. 197-214, 2012.

ALVES, K, S.; MOTA, D. M. Organização do trabalho familiar do espaço rural paraense: novos arranjos na organização do trabalho e na gestão das unidades de produção. Revista Internacional Interdisciplinar INTERthesis, Florianópolis, v. 9, n. 2, p. 191-215, 2012.

BRASIL, S. S. Trabalho, adoecimento e saúde: aspectos sociais da pesca artesanal no Pará. 2009. Dissertação (Mestrado em Ciências Sociais) - Instituto de Filosofia e Ciências Humanas, Universidade Federal do Pará, Belém.

BORCEM, E. R.; FURTADO-JÚNIOR, I.; ALMEIDA, I. C.; PALHETA, M. K. S.; PINTO, I. A. A atividade pesqueira no município de Marapanim-Pará, Brasil. Revista de Ciências Agrárias, Belém, v. 54, n. 3, p. 189-201, 2011.

BRUMER, A. A problemática dos jovens rurais na pós-modernidade. In: CARNEIRO, M. J.; CASTRO, E. G. de (Org.). Juventude rural em perspectiva. Rio de Janeiro: Mauad X, 2007, p. $35-51$.

BRUMER, A. As perspectivas dos jovens agricultores familiares no início do século XXI. In: RENK, A.; DORIGON, C. (Orgs.). Juventude rural, cultura e mudança social. Chapecó: Argos, 2014. p. 115-138. 
CARNEIRO, M. J. O ideal rurbano: campo e cidade no horizonte dos jovens. In: SILVA, F. C. T. et al. (Orgs.). Mundo rural e política: ensaios interdisciplinares. Rio de Janeiro: Campus, 1998. p. 97-117.

CHAMPAGNE, P. Elargissement de l'espace social et crise de l'identidade paysanne. Cahier d'Economie et Sociologie Rurales, n. 3, 1986.

COSTA, A. M. S. Fatores econômicos e culturais na agricultura familiar: um estudo sobre o oeste catarinense. 2010. Dissertação (Mestrado em Magister Scientiae) - Universidade Federal de Viçosa, Viçosa.

COSTA, J. S. P.; BENTES, A. B.; CRUZ, P. A. P.; PEREIRA, L. J. G.; FERNANDES, S. C. P.; FONTES, V. B.; LIMA, W. M. G.; BENTES, B. Produção e socioeconomia do sistema caranguejouçá em unidade de uso sustentável da costa norte do Brasil. Arquivos de Ciência do Mar, Fortaleza, v. 46, n. 2, p. 76-85, 2013.

FIGUEIREDO, J. F.; RIBEIRO, S. C. A.; PONTES, A. N.; SILVA, L. M. Desafios dos catadores de caranguejos na reserva extrativista Marinha Maracanã, Pará, Brasil. Enciclopédia Biosfera, Goiânia, v. 10, n. 18, p. 3225-3236, 2014.

GARCEZ, D. S.; BOTERO, J. I. S. Comunidades de pescadores artesanais no estado do Rio Grande do Sul, Brasil. Atlântica, Rio Grande, v. 27, n. 1, p. 17-29, 2005.

INSTITUTO BRASILEIRO DE GEOGRAFIA E ESTATÍSTICA (IBGE). Banco de dados agregados - 2019. Disponível em: http:// https://cidades.ibge.gov.br/brasil/pa/maracana/panorama. Acesso em: 12 jan. 2019.

ISAAC, V. J.; MARTINS, A. S., HAIMOVICI, M., ANDRIGUETTO, J. M. A Pesca marinha e estuarina do Brasil no início do século XXI: recursos, tecnologias, aspectos socioeconômicos e institucionais. Projeto Recos: uso e apropriação dos recursos costeiros. Grupo Temático: Modelo Gerencial da Pesca. Belém: Editora Universitária UFPA, 2006.

KISCHENER, M. A.; KIYOTA, N.; PERONDI, M. A. Sucessão geracional na agricultura familiar: lições apreendidas em duas comunidades rurais. Mundo agrário, v. 16, n. 33, 2015.

KIYOTA, N.; PERONDI, M. A. Sucessão geracional na agricultura familiar: uma questão de renda? In: BUAINAIN, A. M. et al. (Editores técnicos). O mundo rural no Brasil do século 21: a formação de um novo padrão agrário e agrícola. Brasília: Embrapa, 2014. p. 1011-1045.

MARINHO, M. S. Pesca artesanal, defesos de pesca e unidades de conservação. In: ANADIR: ENCONTRO NACIONAL DE ANTROPOLOGIA DO DIREITO, São Paulo, 20-21 ago. 2009. Anais... São Paulo, USP, p. 1-15, 2009.

MENDONÇA, J. T.; LUCENA, A. C. M.; MUEHLMANN, L. D.; MEDEIROS, R. P. A socioeconomia da pesca no litoral do estado do Paraná (Brasil) no período de 2005 a 2015. Desenvolvimento e Meio Ambiente, Curitiba, v. 41, p. 140-157, 2017. 
MIRALHA, W.; HESPANHOL, R. A. M. Do campo para a cidade: êxodo rural dos jovens, questão sucessória e o envelhecimento dos produtores familiares no município de Álvares Machado. São Paulo: FCT/UNESP, 2003.

MPA. Boletim Estatístico da Pesca e Aquicultura - Ano 2011. Brasília, DF: MPA, 2012. 60p.

NOGUEIRA, L. S. M.; SOUZA, D. M.; SANTA BRÍGIDA, A. M. B. Segurança e saúde dos pescadores artesanais no estado do Pará. São Paulo: Fundacentro, 2017.

PAIOLA, L. M.; TOMANIK, E. A. Populações tradicionais, representações sociais e preservação ambiental: um estudo sobre as perspectivas de continuidade da pesca artesanal em uma região ribeirinha do rio Paraná. Acta Scientiarum, Maringá, v. 24, n. 1, p. 175-180, 2002.

RAINHA, F. A. A pesca artesanal brasileira: uma análise da produção pesqueira em diferentes escalas. In: VII Congresso Brasileiro de Geógrafos, 2014, Vitória, 10 a 16 de agosto, p. 1-12.

RODRIGUES, P. L.; GUIMARÃES, J. B.; MARTINS, C. M.; SANTOS, M. A. S.; REBELLO, F. K. Dinâmica socioeconômica e organizacional em comunidade remanescente do quilombo Rio Gurupá, Marajó, Pará. Revista Verde de Agroecologia e Desenvolvimento Sustentável, Pombal, v. 12, n. 1, p. 105-116, 2017.

SANTANA, A. C.; BENTES, E. S.; HOMMA, A. K. O.; OLIVEIRA, F. A.; OLIVEIRA, C. M. Influência da barragem de Tucuruí no desempenho da pesca artesanal, estado do Pará. Revista de Economia e Sociologia Rural, Piracicaba, v. 52, n. 2, p. 249-266, 2014.

SANTOS, M. A. S. A cadeia produtiva da pesca artesanal no estado do Pará: estudo de caso no nordeste paraense. Amazônia: Ciência \& Desenvolvimento, Belém, v. 1, n. 1, p. 61-81, 2005.

SILVEIRA, E. M.; SERAFIN, S. R. F.; SIQUEIRA, A. B. Novos olhares sobre a pesca artesanal na Lagoa do Mirim: uma abordagem etnoecológica. In: Anais do IV Simpósio sobre Formação de Professores - Simfop, 2012, Santa Catarina: Unisul, 7 a 11 de maio, p. 1-10.

SOUSA, G. M. R.; ROJAS, G. G.; NUNES, E. M.; REIS, J. N. P.; BENTO, J. A. N. Análise do capital social da agricultura no município de Pentecoste (CE). Revista de Estudos Sociais, Cuiabá, v. 17 , n. 35 , p. 83-100, 2015.

STROPASOLAS, V. L. Os desafios da sucessão geracional na agricultura familiar. Agriculturas, v. 8, n. 1, p. 26-29, 2011.

Artigo recebido em 17/01/2020. Aceito para publicação em 06/04/2020. 